\title{
UNA APROXIMACIÓN A UN NUEVO CAMPO DE ESTUDIO SOBRE LA TRANSICIÓN DEMOCRÁTICA. LOS INICIOS DE LA COMUNICACIÓN POLÍTICA TELEVISIVA EN ESPAÑA
}

Virginia Martín-Jiménez: Universidad de Valladolid. España virgimj@hmca.uva.es

\section{RESUMEN}

Este artículo ofrece una aproximación a una investigación, fruto de la tesis doctoral de la autora, que examina el papel político y social que jugó Televisión Española durante los años de la Transición marcados por el consenso, con el fin de comprobar hasta qué punto la cadena pública fue un factor determinante en la conclusión exitosa de un proyecto muy concreto de cambio democrático. La fuente principal para la elaboración de este trabajo fue la programación de contenido político e informativo emitida por TVE ante los hitos clave de esa etapa y las entrevistas personales a profesionales de la comunicación testigos de aquellos años de cambio; junto con encuestas, análisis de audiencia, documentación del Congreso de los Diputados, prensa nacional y una amplia bibliografía.

PALABRAS CLAVE: Transición democrática - Televisión Española Comunicación política - Adolfo Suárez

\footnotetext{
${ }^{1}$ Autor correspondiente

Virginia Martín Jiménez ${ }^{1}$ : Profesora de Periodismo. Universidad de Valladolid. Valladolid. España Correo: virgimj@hmca.uva.es
} 


\title{
AN APPROACH TO A NEW FIELD OF STUDY ABOUT DEMOCRATIC TRANSITION. THE ORIGINS OF POLITICAL COMMUNICATION IN TELEVISION IN SPAIN
}

\begin{abstract}
This article is an outcome of the doctoral thesis defended in 2011 by the author. This research seeks to show how state television in Spain played an important social and political role during years of transition marked by consensus. TV became a key element in the strategy for change during transition and was an important factor in the successful conclusion of a very specific project of democratic change. The main source of this article was the political content of TV during the most important moments of Transition, personal interviews to journalists, surveys, analysis of audience, documentation of the Congress, national press and an extensive bibliography.
\end{abstract}

KEY WORDS: Democratic transition - State television - Political communication Adolfo Suárez

\section{INTRODUCCIÓN}

\subsection{Marco teórico, planteamiento y límites cronológicos}

El presente artículo pretende ser una aproximación a la investigación que la autora de estas líneas llevó a cabo con motivo de la elaboración de su tesis doctoral, defendida con éxito en junio de 2011 (Martín Jiménez, 2011). Esta tesis ha sido realizada bajo la dirección del catedrático Celso Almuiña Fernández. El punto de partida nació de un balance historiográfico que reflejaba un llamativo vacío en relación a los estudios elaborados en el campo de la comunicación y la historia sobre la etapa de la Transición democrática y el papel que jugaron en ella los medios audiovisuales.

Este balance ofrecía un panorama general en el que llamaba la atención que tanto los expertos en la Transición española como los estudiosos de los medios de comunicación estaban de acuerdo en que la televisión había sido un factor histórico fundamental durante la transición de la dictadura franquista a la democracia ${ }^{2}$.

\footnotetext{
${ }^{2}$ Entre los autores que han publicado obras sobre TVE destacan M. Palacio (2006, 2001), E. Bustamante (2006), J. C. Rueda junto con C. Coronado, $\mathrm{M}^{\mathrm{a}}$ del M. Chicharro $(2009,2006)$, J. Barroso y R. Tranche (1996), P. J. Smith (2006); desde un punto de vista más divulgativo, L. Díaz (2006), Y. Veiga e I. Ibáñez (2006); sobre la programación de ficción, la producción historiográfica del grupo de investigación dirigido por M. Palacio de la Universidad Carlos III de Madrid; acerca de documentales, S. Hernández Corchete (2008); el entretenimiento, E. Guerrero (2010); los públicos televisivos, J. F. Gutiérrez
} 
Sin embargo, a pesar de su potencial influencia en la opinión pública y de que se haya reconocido el destacado papel que desempeñó durante la Transición, aún no se había llevado a cabo una investigación que comprobara en qué medida la televisión fue un factor determinante del éxito de un proyecto muy concreto de cambio democrático.

Teniendo en cuenta el estado de la cuestión y la ausencia de investigaciones sobre Televisión en la Transición, en las que se hubieran empleado como fuentes los contenidos políticos de la cadena, los estudios de opinión pública y los testimonios de los profesionales del periodismo, se decidió hacer de ese vacío historiográfico el eje central en torno al cual se elaborarían los objetivos de esta investigación.

Con ese fin, se delimitó cronológicamente esta tesis doctoral de la siguiente manera. El punto de partida quedó situado a mediados de 1976, es decir, la llegada de Adolfo Suárez a la presidencia del Gobierno y, como consecuencia, la instauración de una política de consenso ante la ausencia de un marco legal democrático. Y, el límite final escogido fueron las primeras elecciones generales y municipales celebradas a mediados de 1979 bajo el amparo de la Constitución.

Esta elección se debió al interés que encerraba estudiar el papel que jugó Televisión Española en los años durante los que se produjo el inicio de la democracia en España y en los cuales, ante la falta de unas garantías democráticas, sería el espíritu de consenso el que marcaría, en todos los ámbitos incluido el mediático, las pautas de actuación y los límites de las mismas.

Escaloñilla (Escaloñilla, 2003) Con una delimitación cronológica más concreta, la tesis doctoral de Pérez Ornia (1988) -La televisión y los socialistas. Actividades del PSOE respecto a la televisión durante la transición (1976-1981y, por otra parte, la monografía de Virginie Philippe (2007), Transition et television en Espagne. Le role de la TVE, 1973-1978.

\section{METODOLOGÍA}

Partiendo de ese contexto histórico delimitado, se estableció como objetivo principal de esta investigación comprobar qué lugar ocupó la televisión gubernamental dentro de la estrategia democratizadora del gobierno de Suárez, desde el punto de vista de la comunicación política y la promoción del cambio social. Es decir, demostrar si Televisión Española constituyó un instrumento más de la maniobra de consenso que se puso en marcha tras la llegada de Suárez al poder, con el fin de democratizar la política y la sociedad españolas.

Una vez que ya estaba claro cuál era la base historiográfica de la que se partía, la delimitación cronológica y el objetivo principal, se elaboró la siguiente hipótesis: Televisión Española, aprovechándose del monopolio del que gozaba, de la ausencia de un marco legal democrático y de la amplia audiencia a la que se dirigía a diario, pudo actuar durante los años del consenso democratizador como un medio de 
comunicación al servicio de los intereses políticos y sociales de un proyecto muy concreto de Transición liderado por el Monarca y dirigido por Adolfo Suárez. En este sentido, la cadena estatal se convertiría en el nuevo escenario de la comunicación política y en una de las más destacadas instancias socializadoras en el ámbito de la cultura democrática.

Pero, una vez que ya existiera un respaldo jurídico, gracias a la Constitución de 1978, y que se hubiera dado por terminado el consenso, comenzaría el juego político propio de los gobiernos parlamentarios. Con lo cual, la oposición gubernamental y la prensa, posiblemente endurecieran sus críticas ante los contenidos de la televisión pública. Esta acción crítica pudo ser la causa de que creciera la demanda de un estatuto que garantizara que el partido en el Gobierno ya no pudiera servirse de la televisión pública en beneficio de sus propios intereses.

Puesto que la historia de la Transición y los contenidos televisivos que se emitieron en esa etapa de cambio no pueden comprenderse en su totalidad si se analiza la una al margen de los otros se optó por una metodología interdisciplinar que combinara el estudio histórico de la Transición, el análisis de los contenidos emitidos por la cadena estatal y la posible incidencia de esas emisiones en la opinión pública.

De ahí que el primer paso fuera seleccionar cuáles fueron las claves del proceso democratizador - como el papel del presidente del Gobierno y del Rey, las elecciones generales, la violencia terrorista o la crisis económica - para, una vez escogidos esos hitos principales, poder visionar en los archivos de Televisión Española aquellos espacios - principalmente debates, reportajes y programas informativos- de la parrilla televisiva relacionados con esas claves del proceso, con el fin de analizarlos desde un punto de vista cualitativo, de fondo y forma, e interdisciplinar.

Teniendo en cuenta los objetivos fijados y los hitos claves que habían sido seleccionados, la principal fuente de esta tesis debían ser las emisiones televisivas que guarda el archivo de Televisión Española. Un trabajo de campo que se prolongó durante casi dos años a lo largo de los cuales se llegaron a visionar unas 200 cintas.

Además, aprovechando que esta investigación se centra en una etapa histórica reciente, fue posible entrevistar, a fondo y cara a cara, a profesionales de la comunicación, principalmente trabajadores de TVE, que fueron testigos directos de la Transición. Por ejemplo, se entrevistó a Rafael Ansón Oliart que fue director general de Radiotelevisión Española durante los primeros años de la Transición y además dirigió las campañas electorales y de referéndum que se analizan en esta tesis.

También se entrevistó a Fernando Ónega. La riqueza de sus declaraciones se debe a que él es el autor de gran parte de los mensajes televisados de Adolfo Suárez, y con lo cual, conocía bien de cerca las estrategias comunicativas en las que se basaban las actuaciones mediáticas del presidente. 
Además, a la par que era guionista y presentador de varios espacios de debate de actualidad política en la cadena estatal fue un cercano colaborador de Suárez y dirigió el Gabinete de Prensa de Presidencia.

Por otra parte, los periodistas, Eduardo Sotillos y Miguel Ángel Gozalo, directores, respectivamente, de la segunda edición del Telediario y del informativo de noche del segundo canal aportaron información relacionada con la transformación que vivieron los noticiarios tras la llegada de Rafael Ansón a la dirección de la cadena pública. Sus declaraciones sirvieron para comprender dónde estaban los límites de la información que se transmitía, cómo se trabajaba a diario en la televisión estatal y qué supuso la sustitución de Ansón por el nuevo director general Fernando Arias Salgado a finales de 1977.

Por otra parte, Informe Semanal ha sido uno de los programas que más se ha empleado para elaborar esta investigación; con lo cual fue esencial el testimonio de Pedro Erquicia, periodista que puso en marcha este programa en 1973 y que lo dirigió durante, prácticamente, el periodo que abarca esta tesis. Por otra parte, al tratarse de un profesional que había trabajado en la cadena estatal bajo el régimen franquista, su entrevista ayudó a comprender cómo se adaptaron los periodistas cuando se produjo el cambio de régimen.

En relación con la importancia de Informe Semanal, y en un intento por recabar testimonios directos de mujeres que pudieran aportar información acerca de la imagen del colectivo femenino que transmitió la televisión, se entrevistó a Rosa María Mateo -presentadora habitual de varios espacios de Televisión y, especialmente, de Informe Semanal- y a Carmen Sarmiento, miembro del equipo del programa dirigido por Erquicia y una gran promotora de los derechos de la mujer a través de sus reportajes.

A su vez, para conocer el tratamiento que dio la cadena pública a la información internacional, se contó con las aportaciones de Diego Carcedo; quien además, como enviado especial al País Vasco ante determinados acontecimientos relacionados con acciones terroristas, ayudó a comprender cómo fue ofrecida al público esta información tan delicada.

Y, por último, puesto que la prensa es también una de las fuentes de esta tesis, se juzgó interesante entrevistar a Juan Luis Cebrián, director en aquel momento de El País; uno de los periódicos que fue más crítico con Televisión Española y cuya aportación como "parlamento de papel" al desarrollo de la Transición ha sido reconocida en muchas investigaciones. 
El testimonio de todos ellos, que tanto ha enriquecido esta tesis, permitió ahondar en los contenidos visionados, contrastar informaciones, conocer el porqué de ciertas actuaciones y sobre todo comprender lo que para aquellos profesionales supuso el cambio democrático y lo que aquel contexto histórico pudo influir en el resultado final -el enfoque, los objetivos- de su trabajo periodístico.

Pero no sólo se empleó como fuente los contenidos del archivo de Televisión Española y las entrevistas personales sino que también se acudió al Centro de Investigaciones Sociológicas (CIS) para consultar las encuestas que esta institución llevó a cabo durante la Transición; al Estudio General de Medios (EGM) para conocer los índices de audiencia; y a las hemerotecas de los principales periódicos y revistas de tirada nacional como El País, ABC, Diario 16 y otras, más cercanas a la cadena estatal como la revista Tele-Radio. Además, junto a una exhaustiva consulta bibliográfica, también se acudió al Archivo del Congreso de los Diputados con el fin de conocer la reacción de los parlamentarios ante los contenidos emitidos por Televisión Española.

\section{ANÁLISIS Y DISCUSIÓN}

\subsection{Estructura de la investigación}

A partir del análisis de la documentación aportada por cada una de estas fuentes se estructuró la tesis en ocho capítulos. En primer lugar se trató de introducir al lector en el marco histórico y audiovisual en el que se desarrolla la tesis doctoral. Tras esta introducción contextual, se describieron, en el segundo capítulo, los primeros pasos que se dieron durante la Transición en la conformación de una democracia mediática; puesto que Adolfo Suárez, como presidente del Gobierno y bajo las pautas del director general de televisión Rafael Ansón, al dar protagonismo a la televisión, llevó a cabo un cambio en el escenario de la comunicación política española ${ }^{3}$. Así, en diciembre de 1976 se convocó el referéndum de la Ley para la Reforma Política y con él llegó el primer gran reto de la "vídeo-política" española, si empleamos el término acuñado por Sartori ${ }^{4}$.

\footnotetext{
${ }^{3}$ En este sentido nos hemos basado en el concepto comunicación política que defiende Juan Ignacio Rospir. Como bien ha explicado este autor, la comunicación política surge únicamente en contextos de democracia (o de instauración de ella, como es el caso que nos atañe ahora); puesto que ante otro tipo de régimen estaríamos hablando de propaganda y no de comunicación política. José Ignacio (2003): "Introducción a la comunicación política", Berrocal, S. (coord.), Comunicación política en televisión y nuevos medios. Ariel. Barcelona. Págs. 22-54. Sin embargo, para otros estudiosos como María José Canel, la comunicación política es un término más amplio que incluye fenómenos comunicativos tan variados como la propaganda, el marketing electoral, marketing político, relaciones públicas políticas y comunicación institucional política. CANEL, María José (2006): Comunicación política. Tecnos. Madrid.

${ }^{4}$ El término de "vídeo-política", acuñado por Giovanni Sartori, "hace referencia no sólo a uno de los múltiples aspectos del poder del vídeo [TV]: su incidencia en los procesos políticos y con ellos una radical transformación de cómo ser políticos y de cómo gestionar la política. (...) El pueblo soberano opina
} 
Una vez logrado el respaldo en las urnas a dicha ley, como se puede leer en el tercer capítulo, se convocaron unas elecciones generales que se celebraron el 15 de junio de 1977. Por primera vez en la historia de la nación española, políticos de todas las tendencias se dirigieron al electorado desde la pequeña pantalla para pedirles su voto.

Por otra parte, el consenso que, como ya he comentado, marcó el devenir del cambio democrático, se concretó en dos grandes acuerdos: Los Pactos de la Moncloa y la Constitución de 1978, que protagonizan el cuarto capítulo. Teniendo en cuenta la trascendencia, fundamentalmente económica, del primero de ellos se analizó la repercusión que tuvieron en la pequeña pantalla y el tratamiento que se dio a la crisis en la programación televisiva.

En relación con la Carta Magna se expuso la cobertura que la televisión ofreció a su elaboración y el despliegue informativo ante el referéndum; el cual marcó el final de una "teledemocracia" construida en torno al espíritu de consenso que había movido los hilos de la Transición.

Con la Constitución de la mano, se dio por terminado el consenso. Y todo un ejemplo de lo que supuso la ruptura del consenso serán las elecciones generales y municipales celebradas a mediados de 1979, que fueron tratadas en otro capítulo de esta tesis.

Por otra parte, la historia de la Transición estuvo determinada, en gran medida, por la figura del Rey Juan Carlos I; por ese motivo se dedicó el sexto capítulo de la tesis a estudiar la imagen del Monarca ofrecida desde la cadena pública. A su vez, en uno de los capítulos finales de esta investigación, el séptimo, se trató de encontrar las pautas informativas que lograron contraponer el elevado número de acciones perpetradas por diversas bandas terroristas con la proyección de un cambio democrático pacífico que se transmitió desde la televisión y que se ha perpetuado en el imaginario social hasta la actualidad.

Por último, el octavo, se centra en la acción socializadora en nuevos valores y prácticas democráticas, como la igualdad de género o la pluralidad nacional, que se desplegó desde la cadena estatal.

\section{CONCLUSIONES}

A lo largo de estos ocho capítulos se fueron alcanzando los objetivos marcados a la vez que comprobaba cómo se cumplían las hipótesis fijadas al comienzo de la elaboración de la tesis. Entre las principales conclusiones a las que se llegó destacan las siguientes:

Desde mediados de 1976, el Rey Juan Carlos I y el presidente Adolfo Suárez se enfrentaron al gran reto de conducir al país hacia un cambio democrático partiendo de la reforma del régimen anterior. Para lograr con éxito este continuismo reformista 
era indispensable contar con el consenso de todos los agentes políticos y sociales. Ese consenso se convirtió en el eje vertebrador alrededor del cual se construyeron los cimientos del cambio de régimen.

Para que esta voluntad de concierto diera sus frutos era indispensable que la opinión pública respaldara las decisiones de los dirigentes de la Transición y formara parte también de ese compromiso. Para conformar ese consentimiento era preciso desplegar una estrategia en torno a un medio de comunicación, como era la televisión, que no sólo estaba manejado directamente desde el Estado sino que a su vez ejercía una destacada influencia en la ciudadanía.

Los dirigentes de la Transición eran conscientes de la potencial influencia que tenía la pequeña pantalla ${ }^{5}$. Por eso, diseñaron un plan televisivo para lograr que los españoles apoyaran a los artífices del cambio y fueran respaldando cada una de las decisiones que se tomaran desde el Gobierno, al mismo tiempo que se producía una socialización en política democrática. La televisión, por tanto, como espacio informativo, instancia socializadora y legitimadora que es, se convirtió en un marco de referencia para la opinión pública.

Por otra parte, durante los inicios de la Transición, tuvo lugar un cambio en el escenario de la comunicación política, de ahí que podamos hablar de la irrupción de la "vídeo-política" o de la "teledemocracia" (Maarek, 2009).

Así, a través de la superposición de la agenda informativa y la gubernamental la dirección del medio estatal se volcó ante los hitos claves de la Transición, como sucedió, por ejemplo durante el referéndum de la Ley para la Reforma Política, las primeras elecciones generales celebradas en junio de 1977, el referéndum constitucional o la aprobación de los Pactos de la Moncloa.

Como tercer punto dentro de las conclusión, hay que destacar que frente a esas conquistas que fueron jalonando la Transición, aparecieron grupos terroristas, como ETA, el GRAPO o la extrema derecha, que ensangrentaron el discurrir del cambio. Frente a esta violencia -recordemos que hubo casi 300 muertes entre 1976 y 1979- la televisión, sin dejar de mantener informados a los espectadores, silenció en cierta medida la repercusión de estos actos y eludió cualquier tipo de análisis profundo que fuera más allá de la mera retransmisión de la información o la crónica del suceso.

Así pues, ante la reiterada violencia terrorista y los escollos que hubo que superar a lo largo de la Transición, -tales como la crisis económica, las tensiones internas, las reivindicaciones nacionalistas-que hacían temer la radicalización de las circunstancias

\footnotetext{
${ }^{5}$ En aquel momento, el equipamiento de televisores cubría ya el $93 \%$ del territorio español y más del 90\% de la población declaraba que veía la televisión todos o casi todos los días, mientras, a pesar de lo mucho que se ha idealizado el papel de la prensa, el número de lectores de periódicos no hacía más que
} 
político-sociales, fue primordial la perspectiva desde la que Televisión Española enfocó todas estas cuestiones; logrando finalmente la reunificación de la opinión pública alrededor de fundamentos democráticos y pacifistas. La fe en la Transición que irradiaban las cámaras y la imagen de normalidad absoluta que reflejaban sus programas, avivó "la espiral del silencio" (Noelle-Neumann. 1995) en torno a los sectores sociales que añoraban el pasado o que no eran nada partidarios de la reforma tal y como se estaba llevando a cabo.

En cuarto lugar vemos cómo desde la campaña del referéndum de la Ley para la Reforma Política -como el punto de partida de la "teledemocracia"- hasta las primeras "vídeo-elecciones" (junio de 1977), pasando por la defensa en la televisión de los Pactos de la Moncloa, la campaña del referéndum constitucional o las de los comicios generales y municipales de 1979, se observa una clara evolución de la comunicación política en la televisión. Esta, de manera paulatina y adentrándose en un terreno completamente virgen en España, fue adoptando los rasgos propios del american style; a la par que el foco de atención en las campañas se fue desplazando a los espacios televisivos de la cadena pública, es decir, al decisivo "mitin del cuarto de estar".

Tanto por la actitud del presidente del Gobierno ante la televisión, por los conocimientos que de este medio tenía, puesto que había sido su director años atrás (Hernández. 2009);(Abella. 2006), como por la posibilidad que se les ofreció al resto de las fuerzas políticas de asomarse a las cámaras ante los hitos claves del cambio, se podría concluir que la televisión se convirtió a finales de la década de los setenta en un medio de relación directa entre los políticos y los ciudadanos.

De esta manera, a través de los mensajes de Suárez y los miembros del parlamento, las campañas televisivas o los contenidos de la programación habitual, la pequeña pantalla sirvió como un instrumento de transmisión de la Transición democrática, al mismo tiempo que trabajaba con el fin de propiciar una opinión pública que respaldara las decisiones de los dirigentes del proceso.

Teniendo esto en cuenta, podría decirse que, en gran medida, en este paso de un régimen dictatorial a una democracia, se intentó gobernar la nación desde las cámaras de la televisión pública. A través de una "política de visibilidad" (Ortega. 2003. p. 71), de un diálogo permanente entre la pantalla y los espectadores, los dirigentes del cambio transmitieron a la audiencia la sensación de que cada uno de los españoles estaba implicado en el proceso de cambio como si este fuese una tarea colectiva.

En quinto lugar, en TVE se trabajó, al igual que en el ámbito político, a partir de un equilibro entre continuismo y ruptura. Un ejemplo de este equilibro lo podemos encontrar en los programas de debate que se pusieron en marcha. Estos espacios reflejaron unas pautas de comportamiento idénticas a las de los dirigentes del 
Esa actitud dialogante y de consenso que primó en las tertulias se pudo llevar a cabo por la habitual ideología monocolor de sus invitados. Frente a estos espacios, convertidos en una serie de "yuxtaposiciones de diálogos" (Imbert. 1990), encontramos el programa La Clave uno de los ejemplos de lo que se ha venido a denominar en esta tesis el "lavado de cara del sistema"; es decir, todas aquellas excepciones, en la tónica más habitual de la parrilla televisiva, que servían para equilibrar la balanza en el cambio reformista que se llevó a cabo en los contenidos de la cadena pública.

Los profesionales de la televisión también optaron por ese equilibrio que garantizó una conformidad y una permisividad hacia ciertas actuaciones gubernamentales so pretexto de que únicamente se perseguía la instauración de una democracia, a pesar de que esto significara en ocasiones tener que poner límites a la información y a la opinión que se exponía ante las cámaras. No se está defendiendo que existiera censura en la televisión pública, en el sentido más estricto de manipulación, sino que durante los primeros años de la Transición, el consenso también rigió el quehacer diario de los profesionales de la cadena estatal: "de las consignas se pasó a las conveniencias", en palabras del periodista Miguel Ángel Gozalo (entrevista personal, marzo 2010). Es decir, entre los trabajadores de este medio, existió un compromiso común, no escrito, de colaborar con responsabilidad en la instauración de un sistema democrático, de convertir a España en un país europeo y de no provocar una nueva guerra civil.

Dentro de este equilibrio nacido del consenso, y como siguiente conclusión, sí hubo algo realmente intocable en la televisión de la Transición: la figura del Rey y la institución que encarnaba.

Los periodista, que habían conocido la censura franquista, estaban acostumbrados a trabajar entre límites que o bien venían impuestos "desde arriba" o, en otras ocasiones, eran ellos mismos quienes los imponían (autocensura). Pues fue este último mecanismo el que siguió existiendo habitualmente en televisión: no hacía falta que las directrices marcaran cómo actuar ante la Corona porque de sobra sabían que esta era indiscutible, puesto que sobre ella se habían levantado los cimientos del nuevo régimen.

Como se ha apuntado anteriormente, y como última conclusión, una vez que ya se pusieron las bases de ese sistema político, es decir cuando ya hubo un respaldo jurídico -la Constitución de 1978- se dio por terminado el consenso. Comenzaba así el verdadero juego político propio de los gobiernos parlamentarios $\mathrm{y}$, por lo tanto, ya no se iban a consentir ciertas prácticas que antes se justificaban de cara a esa meta común democratizadora. La ruptura del consenso, ejemplificada en las campañas electorales de 1979, supuso un cambio en la actitud de la oposición política y de los medios escritos, quienes comenzaron a endurecer sus críticas a la televisión pública y a exigir que se regulara la actuación de este medio a través de un estatuto. 
Para terminar estas páginas, habría que puntualizar que a pesar de la relevancia histórica que esta tesis otorga a la televisión durante la Transición no pretende en ningún momento hacer de ella el único factor que explique el discurrir de la Transición. Consideramos que fueron muchos los agentes que colaboraron en el cambio democrático que vivió España tras el final de la dictadura; sin embargo, como se ha tratado de exponer en esta investigación, desde mediados de 1976 la política y la televisión estuvieron tan entrelazadas que no se puede comprender la evolución de la Transición democrática y su resultado final sin tener en cuenta la imagen, que de esa realidad de cambio democrático, recibieron los espectadores-ciudadanos a través de Televisión Española.

Por otra parte, esta investigación no busca ofrece unas conclusiones cerradas sino que persigue abrir nuevos interrogantes y provocar el interés de la comunidad científica en el estudio riguroso de nuestro pasado más reciente desde un punto de vista interdisciplinar que posibilite ir más allá de la mera narración del recuerdo a través de la reproducción de testimonios y que suponga un esfuerzo de análisis riguroso de la historia de la comunicación y de los contenidos mediáticos en clave de la influencia socio-política que han ejercido los medios de comunicación ante los hitos más relevantes de episodios tan destacados de nuestro pasado más reciente como la Transición democrática.

\section{REFERENCIAS}

Abella, C. (2006). Adolfo Suárez. Madrid: Espasa Calpe.

Barroso, J. \& Tranche, R. (1996). Televisión en España. Archivos de la Filmoteca. No 23-24, junio-octubre. Madrid.

Bustamante, E. (2006). Radio y televisión en España. Historia de una asignatura pendiente de la democracia. Barcelona: Gedisa.

Canel, M. J. (2006). Comunicación política. Madrid: Tecnos.

Díaz, L. (2006). 50 años de TVE. Madrid: Alianza.

Guerrero, E. (2010). El entretenimiento en la televisión española. Historia, industria y mercado. Barcelona: Deusto.

Gutiérrez Lozano, J. F. (2006). La televisión en el recuerdo. La recepción de un mundo en blanco y negro en Andalucía. Málaga: Universidad de Málaga. RTVA.

Gómez Escaloñilla, G. (2003). Programar televisión. Análisis de los primeros cuarenta años de programación televisiva en España. Madrid: Universidad Rey Juan Carlos.

Hernández, A. (2009). Suárez y el Rey. Madrid: Espasa Calpe. Madrid. 
Hernández Corchete, S. (2008). La historia contada en televisión. El documental televisivo de divulgación histórica en España. Barcelona: Gedisa.

Imbert, G. (1990). Los discursos del cambio. Imágenes e imaginarios sociales en la España de la transición (1976-1982). Madrid: Akal.

Maarek, P. J. (2009). Marketing politico y comunicación. Claves para una buena información politica. Barcelona: Paidós.

Martín Jiménez, V. (2011). Televisión Española y la Transición democrática: Comunicación politica y promoción del cambio social durante la etapa del consenso (19761979). Tesis doctoral dirigida por Dr. D. Celso Almuiña Fernández. Universidad deValladolid (inédita).

Mateos- Pérez, J. (2008). A la caza del espectador. Estrategias de programación en los inicios de la televisión privada en España (1990-1994). Madrid: Universidad Complutense.

Noelle- Neumann, E. (1995).La espiral del silencio. Barcelona: Paidós.

Ortega, F. (2003). Una simbiosis compleja: políticos y periodistas. Telos, 54.

Palacio, M. (2006). Las cosas que hemos visto. 50 años y más de TVE. Madrid: Instituto RTVE.

Palacio, M. (2001). Historia de la televisión en España. Barcelona: Gedisa.

Munsó Cabús, J. (2001): La otra cara de la televisión. 45 años de historia y política audiovisual. Flor del Viento.

Pérez Ornia, J. R. (1988). La televisión y los socialistas. Actividades del PSOE respecto a la televisión durante la transición (1976-1981). Madrid: Editorial de la Universidad Complutense.

Philippe, V. (2007). Transition et television en Espagne. Le role de la TVE, 1973-1978. París: L'Harmattan.

Quintana Paz, N. (2007). Televisión y prensa durante la UCD. Premios y castigos mediático-gubernamentales. Madrid: Fragua.

Rueda Laffond, J. C. \& Coronado Ruiz, C. (2009). La mirada televisiva. Ficción y representación histórica en España. Madrid: Fragua.

Rueda Laffond, J. C. \& Chicharro Merayo, M Del M. (2006). La televisión en España 
Rospir, J. I. (2003). Introducción a la comunicación politica, Berrocal, S. (coord.), Comunicación política en televisión y nuevos medios. Barcelona, Ariel.

Sartori, G. (1998). Homo videns. La sociedad teledirigida. Madrid: Taurus.

Smith, P. J. (2006). Television in Spain. From Franco to Almodóvar. Tamesis: Woodbridge..

Veiga, Y. \& Ibáñez, I. (2006). Religión Catódica: 50 años de televisión en España. Madrid: Roma Lama Music.

\section{Virginia Martín Jiménez}

Doctora por la Universidad de Valladolid, licenciada en Periodismo, licenciada en Historia y diplomada en Sociología, Virginia Martín Jiménez es profesora de Periodismo en la Facultad de Filosofía y Letras de la Universidad de Valladolid. Sus líneas de investigación se enmarcan en el ámbito de la comunicación política, los estudios sobre la Transición democrática, la historia de la comunicación social y la conformación de la opinión pública a través de los medios de comunicación. Ha sido investigadora invitada en centros internacionales como la Universidad Carolina de Praga, el Centro de Estudios de la Población, Economía y Sociedad de la Universidad de Oporto o la Universidad Nova de Lisboa. Ha publicado en editoriales como Routledge y Fragua. 